АНДРеЕв В. В., АНДРеЕв В. В.

ПСИХОЛОГИЧЕСКАЯ КОНЦЕПЦИЯ ПРЕОДОЛЕНИЯ: ТЕОРИЯ, МЕТОДОЛОГИЯ, ДИАГНОСТИКА

РосСиЙский психологИЧЕский жУРнАл, 2019, Т. 16, № 3, 20-32. doi: 10.21702/rpj.2019.3.2

\title{
Психологическая концепция преодоления: теория, методология, диагностика
}

\author{
Виталий В. Андреев*, Владимир В. Андреев \\ Национальный государственный университет физической культуры, спорта и здоровья имени \\ П. Ф. Лесгафта, г. Санкт-Петербург, Российская Федерация \\ *E-mail: vitavv2507@yandex.ru \\ ORCID ID: https://orcid.org/0000-0003-4946-3834
}

\begin{abstract}
Аннотация
Ввеление. В статье преАложен анализ френомена «преололения» с различных теоретических и методологических позиций. Представлен терминологический, семантический и функциональный анализ концепта «преололение» в структуре самосознания спортсменов. Показана тесная связь френомена «воли» С концептом «преололение» в различных аспектах. В частности, показаны фрилософрские, психолого-педагогические, психофизиологические, социально-психологические Аетерминанты, влияющие на фрормирование нашего подхода в изучении ореномена преололения. Научная новизна заключается в попытке метолологического и научно-критического анализа проблемы преололения в психологии. Систематизированы концепции отечественных и зарубежных ученых в процессе осмысления френомена «преомолениел. Сорормулировано авторское рабочее опрелеление френомена «преололениел, и вылелены уровни преололения. Впервые комплексно исследован феномен «преололение» с точки зрения ффизических и психологических регуляторных Аетерминант.

Теоретическое обоснование. Приводятся базовые теории, принципы, концепции, включающие: Аиалектический принцип, принцип трансгрессивности, принцип устойчивого неравновесия живых систем, принцип самодетерминации. Приведены основные аспекты психологической теории преодоления. Показано влияние концепции жизнестойкости, наАситуативной теории активности, иАеи пассионарности и лиминальности. Учтены разработки психологии экстремальности, психологических барьеров, проблемы риска. К объяснительным Аетерминантам

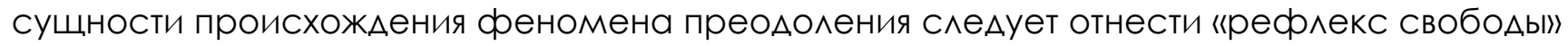
и «рефрлекс цели» И. П. Павлова, «принцип Аоминанты» А. А. Ухтомского, синергетические илеи «концепции неравновесных систем» И. Пригожина, «концепцию пассионарности» ^. Гумилева, теоретические положения П. К. Анохина, Б. Г. Ананьева, Н. А. Бернштейна, Э. С. Бауэра и мругих ученых.
\end{abstract}

Результаты и их обсужаение. Была разработана схема фрункционального анализа ретроспективных автобиографических анкетных данных, предложен алгоритм семантического анализа эмпирических Аанных. По результатам контент-анализа преАставлена структурно-Аинамическая характеристика френомена преололения, выяснены психологические параметры понятий «воли» и «преололения». Выполнен семантический анализ различных преАставлений о ореномене преололения. Прелложена уровневая концепция преололения. Осуществлена попытка концептуализации понятия «воли» и ее связь с парадигмой «преололения». 
АНДРЕЕВ В. В., АНДРЕЕВ В. В.

ПСИХОЛОГИЧЕСКАЯ КОНЦЕПЦИЯ ПРЕОДОЛЕНИЯ: ТЕОРИЯ, МЕТОДОЛОГИЯ, ДИАГНОСТИКА

РосСИЙСКИй пСИХологИЧЕСКИй ЖУРнАл, 2019, Т. 16, № 3, 20-32. doi: 10.21702/rpj.2019.3.2

ОБЩАЯ ПСИХОЛОГИЯ, ПСИХОЛОГИЯ ЛИЧНОСТИ, ИСТОРИЯ ПСИХОЛОГИИ

\section{КАючевые слова}

понятие воли, френомен преололения, уровни преололения, трансгрессия, мотивация, переживание, соріng, неопределенность

\section{Основные положения}

- проблема преололения критических ситуаций имеет и теоретический, и методический, и практический аспекты;

- трансАисциплинарный подхоА в построении концепции преололения вкАючает слеАующие принципы: принцип противоречий, принцип трансгрессии, принцип потенцирования, принцип предельности, принцип субъектности, принцип самодетерминации, принцип неуАовлетворенности, принцип неопреАеленности и принцип опасности;

- уровневая модель преодоления позволяет феномен преололения представить в виле сталий преололевающего восхожАения и преобразования в процессе перехолов с олного уровня активности субъекта на Аругой;

- психологические компоненты преодоления вкАЮчают мотивационный компонент преодо^ения (мотив как первичный результат преололения зависимости); поведенческий компонент преололения (поступок как результат преололения поведенческой некомпетентности); когнитивный компонент преололения (инте^лектуальная активность как результат преололения неопределенности); афофективный компонент преололения (переживание как результат преололения опасности и тревоги);

- вводимые критерии преодоления позволяют измерять процесс преодоления по слеАующим показателям: когнитивный показатель неопреАеленности; афорективный показатель опасности; мотивационный показатель неудовлетворенности; поведенческий показатель некомпетентности;

- паралигма преололения различных ограничений в холе Аеятельности позволяет понять и проанализировать развивающий, обучающий и тренирующий механизм созиАатеАьных си^ ^ичности человека.

\section{Для цитирования}

Андреев, В. В. и Андреев, В. В. (2019). Психологическая концепция преодоления: теория, методология, диагностика. Российский психологический журнал, 16(3), 20-32. doi: 10.21702/rpj.2019.3.2

Дата получения рукописи: 14.07 .2019 Дата окончания рецензирования: 29.08.2019 Дата принятия к публикации: 05.09.2019

\section{Введение}

\section{Парадигма преодоления в науке}

Интерес к проблеме преодоления в науке существовал всегда. Анализ научно-практической зарубежной и отечественной литературы показывает, что, несмотря на имеющиеся работы в этом направлении, проблема повышения способности к преодолению критических ситуаций остается актуальной, т. к. предлагаемые методы ее решения, на наш взгляд, являются малоэффективными. Проблемы, связанные с феноменом преодоления предельных пиковых ситуаций, свидетельствуют, что сложившаяся практика организации педагогической деятельности 
АНДРеЕв В. В., АНДРеЕв В. В.

ПСИХОЛОГИЧЕСКАЯ КОНЦЕПЦИЯ ПРЕОДОЛЕНИЯ: ТЕОРИЯ, МЕТОДОЛОГИЯ, ДИАГНОСТИКА

РосСиЙский психологИЧЕский ЖУРнАл, 2019, Т. 16, № 3, 20-32. doi: 10.21702/rpj.2019.3.2

ОБЩАЯ ПСИХОЛОГИЯ, ПСИХОЛОГИЯ ЛИЧНОСТИ, ИСТОРИЯ ПСИХОЛОГИИ

недооценивает данный феномен. Актуальность, теоретическая, методическая и практическая востребованность предлагаемой темы исследования определяются противоречиями:

- между группой психологов, считающих, что исследование концепции «преодоления» не может быть необходимым и достаточным условием в объяснении специфики феномена воли, и теми психологами, которые считают, что без существенного анализа феномена «преодоления» невозможно продвинуться в исследовании проблемы воли как в теоретическом, так и практическом плане;

- между многочисленными исследовательскими проектами в области изучения критических (стрессовых, конфликтных, кризисных, рискованных, экстремальных) ситуаций и отсутствием смыслового, теоретического и содержательного анализа и описания процесса преодоления критических ситуаций в деятельности человека;

- между широкой изученностью способов поведения в критических ситуациях посредством двух механизмов: психологической защиты (сохранение психики) и копинг-механизмов (приспособление, адаптация психики), и недостаточной разработанностью концепции преодоления в аспекте «сорing behavior» как механизме тренировки, обучения и развития личности.

Существующие противоречия обусловливают проблему изучения концепции преодоления в психологии, педагогике и спорте.

В зарубежной и отечественной психолого-педагогической литературе наиболее точно и корректно феномен преодоления соотносится с «сорing-behavior» (Lazarus \& Folkman, 1984). Понятие «соріng» происходит от английского «соре» (преодолевать, бороться). В германоязычной психологии в этом же смысле используются как синонимы понятия «Bewaltigung» (преодоление) и «Belastungsverarbeitung» (переработка нагрузок)».

Феноменология преодоления достаточно адекватно проявляется при описании таких характерных способов поведения человека, как «ассертивность» (Hobfoll \& Lerman, 1988, с. 565-589), «контроль за действиями» в ситуации преграды и/или неудачи (контрольность) (Kuhl \& Beckmann, 1994; Kuhl, 1994; Kuhl, 1983), «психологическая защита» (Plutchik, Kellermann, \& Conte, 1979), «резилиантность» (Сапогова, 2009), «жизнестойкость» (Мадди, 2002; Maddi, 1965), протестное поведение (Гусейнов, 2017), лиминальность (Сапогова, 2009; Шиповская, 2013), экстремальность (Томалинцев, 2007; Магомед-Эминов, 2008; Caplan, 1963), рискованность (Корнилова, 2003; Петровский, 1992), и др.

Борьба сопровождает всю жизнь человека, и ему приходится прикладывать постоянные усилия не только для внешней, но и для внутренней непрерывной работы. Напряженная жизнь протекает таким образом, что наиболее важные и значимые моменты зависят от напряжений и усилий, совершаемых человеком. Напряжение, усилие и борьба в жизни означают, что чего-то нет и не может возникнуть, пока человек не приложил усилий, не отказался от борьбы. Тогда следует, что весь субъективный мир человека держится и плывет на «гребне волны» психофизических и духовно-нравственных усилий. «И степень достижений у человека будет определяться и различаться в том, кто совершил усилие, а кто его не совершил, кто совершил большее усилие, а кто меньшее» (Мамардашвили, 1997).

Перефразируя любимое определение М. Пруста, ставшее концептуальным лозунгом М. К. Мамардашвили, следует думать, что «человек есть усилие быть человеком, а жизнь - это усилие человека во времени» (Мамардашвили, 1997). «Время теряется там, где любой человек не прикладывает усилий, не берет на себя ответственность в ситуациях неопределенности, 
АНДРЕЕВ В. В., АНДРЕЕВ В. В.

ПСИХОЛОГИЧЕСКАЯ КОНЦЕПЦИЯ ПРЕОДОЛЕНИЯ: ТЕОРИЯ, МЕТОДОЛОГИЯ, ДИАГНОСТИКА

РосСИЙСКИй пСИХологИЧЕСКИй ЖУРнАл, 2019, Т. 16, № 3, 20-32. doi: 10.21702/rpj.2019.3.2

ОБЩАЯ ПСИХОЛОГИЯ, ПСИХОЛОГИЯ ЛИЧНОСТИ, ИСТОРИЯ ПСИХОЛОГИИ

опасности и риска за то, чтобы быть живым. Жизненный опыт с необходимостью заставляет каждого человека быть готовым к напряженной деятельности, к физическим и психическим усилиям, к борьбе с внутренними и внешними силами. Можно с уверенностью сказать, что там, где мы не приложили необходимых усилий, там время и жизнь оказываются утерянными. Профессиональный результат не определен, но он точно зависит от наших усилий. Человек двигается к успеху в той мере, в какой он способен и желает приложить усилия» (Мамардашвили, 1997).

С нашей точки зрения, человек - это «человек преодолевающий», и он существует во всей своей полноте тогда, когда преодолевает себя, преодолевает внутренние и внешние ограничения, преодолевает физические и психические барьеры, и вместе с тем только это позволяет ему состояться и достигнуть спортивного результата. Настоящий человек - это человек, ищущий для себя предельных, экстремальных ситуаций (Ryan \& Deci, 2002; Ryan, Deci, \& Grolnic, 1995; Ryan \& Deci, 2000). Тогда поведение человека в экстремальной ситуации - это как бы весы: их чаша может качнуться в сторону успеха, а может - в сторону неудачи. Тогда риск как форма преодоления жизненных трудностей может быть анализируем как точка неустойчивости, неравновесности, бифуркации, переломного момента между удачей и неудачей, успехом и поражением, потерей и приобретением, - точка равенства шансов.

Уместно вспомнить С. Л. Рубинштейна (1997): «Я непрерывно взрываю, изменяю ситуацию, в которой я нахожусь, а вместе с тем непрерывно выхожу за пределы самого себя, это не есть отрицание моей сущности... это ее становление и вместе с тем реализация моей сущности; не отрицание самого себя и становление, а становление и реализация. Отрицается только мое наличное бытие, моя завершенность, конечность».

Необходимо вспомнить, что еще в конце 70-х гг. была предложена идея анализа теории деятельности через понятие «барьер», однако, к сожалению, дальнейшего продолжения она не получила и была заброшена. Нельзя забывать, что еще К. Д. Ушинский в своих трудах связывал деятельность с понятием «препятствие». Он писал, что без препятствий, средств преодоления, процесса преодоления любая деятельность невозможна (Ушинский, 1953).

В академических психологических кругах понятия «ограничения», «препятствия», «барьеры» воспринимаются в тривиальном, обыденном значении: как нечто лишнее, мешающее, нежелательное. Поэтому предполагается, что с теоретических, методологических и практических позиций эти понятия не играют никакой роли, они не научны. С нашей точки зрения, понятия «ограничения», «препятствия», «барьеры» не только являются постоянным атрибутом педагогической, спортивной и творческой деятельности, но могут нести и концептуальную нагрузку. Присутствие их тотально и всегда можно встретить там, где взаимодействуют какие-то противоборствующие силы. Любая материальная система, состоящая из различных частей, может существовать только за счет разнообразных ограничений, препятствующих ее существованию. Без ограничений и барьеров не может существовать ни один физический объект, без них невозможно развитие любой системы, невозможно существование человечества. Ограничения и барьеры стимулируют, катализируют и собирают энергию-подобно плотине, перекрывающей русло реки. Они же организуют, регулируют, корректируют и упорядочивают различные движения и энергетические потоки. Сам человек стал человеком потому, что научился преодолевать гравитационные силы при ходьбе и беге, сопротивление воды, воздуха, атмосферы, а духовно-нравственный барьер-совесть, не только является духовным стержнем людей, но и опорой в существовании государства, да и всего человечества. 
АНДРеЕв В. В., АНДРеЕв В. В.

ПСИХОЛОГИЧЕСКАЯ КОНЦЕПЦИЯ ПРЕОДОЛЕНИЯ: ТЕОРИЯ, МЕТОДОЛОГИЯ, ДИАГНОСТИКА

РосСИЙскИй псИХоЛОГИЧЕСКИй ЖУРНАл, 2019, Т. 16, № 3, 20-32. doi: 10.21702/rpj.2019.3.2

ОБЩАЯ ПСИХОЛОГИЯ, ПСИхОЛОГИЯ ЛИЧНОСтИ, ИСтОРИЯ ПСИхОЛОГИИ

С нашей точки зрения, парадигма преодоления открывает новые возможности в получение психологических знаний, опираясь только лишь на одно системообразующее понятие - «преодоления». Анализ деятельности по преодолению профессиональных ограничений и препятствий поможет изучить основной источник развития многих психических новообразований, факторов развития, обучения и тренировки различных функций психики и поведения человека и понять их роль в процессе достижений, опираясь только на концепт преодоления.

Исследование феномена преодоления, которое часто выражается в виде психического напряжения (стресс), психического усилия (волевого усилия) и психологии борьбы (борьбы мотивов), поможет определить позитивное влияние предельных факторов на результат в любой профессиональной деятельности.

Принято считать, что воля - это активная сторона сознания, высший уровень работы сознания; она включена в деятельность, выполняет организующую, управляющую, регулирующую, контролирующую и координирующую функции, является центральным психическим образованием, собирает и удерживает в поле сознания все другие функции, а именно сенсорно-перцептивные и когнитивно-эмоциональные, призвана создавать усилие и удерживать его так долго, как это необходимо для достижения цели (результата). Эта способность человека, проявляющаяся в самодетерминации и саморегуляции его деятельности, отражена в работах Maslow (1967), Deci \& Ryan (1991; 1985; 1986; 2002; 1995; 2000, etc.). Воля направляет, активизирует или тормозит действия человека, а также включена в процессы мотивирования, целеполагания, направляет психическую активность на решение проблем, задач и вопросов. Она выступает в качестве инициирующего, мобилизующего и внутреннего факторов деятельности.

По мнению Тульчинского (2002), понятие воли отражает «лишь инстинкт свободы» (с. 454), которая отрицает детерминацию, точнее - антидетерминирована. Латинский корень слова «де-терминация», означает о-пределение, о-пределивание, о-граничение и равнозначен «бес-пределу»- понятию, имеющему двойственный смысл: с одной стороны, имеет негативную установку к общепринятым социальным нормам (цит. по: Леонтьев, 2011, с. 67), с другой стороны, подчеркивается относительность предела-как бы его можно и преодолеть, найти выход за пределами ситуации.

\section{Теоретическое обоснование \\ Принципы преодоления}

Концептуальные подходы в изучении феномена воли как преодоления базируются на общих диалектических принципах, сформулированных еще Гегелем (1974), Мамардашвили (1997), Рубинштейном (1997). Основополагающую роль играет трансгрессивная теория личности Kozielecki (2001; 1997; 1995; 1987), психологическая теория преодоления Шакурова (2003). Опора на модели жизнестойкости С. Мадди и Д. А. Леонтьева (Леонтьев, 2011; Мадди, 2002; Maddi, 1965), на принцип самодетерминации (Леонтьев, 2011), на идеи пассионарности (Гумилев, 2001), на феномен лиминальности (Тульчинский, 2002; Сапогова, 2009), на исследования преодолевающей адаптации (Пакулина, 2010) расширяет понимание нашего подхода. К изучению феномена воли как преодоления важное дополнение привносят принцип устойчивого неравновесия живых систем Бауэра (1935), надситуативная теория активности Петровского (1992), теоретические положения неравновесных систем И. Пригожина, разработки проблемы экстремальности (Магомед-Эминов, 2008; Разумовский, 1988; Томалинцев, 2007). Трансдисциплинарный подход позволяет учесть теорию ограничений в экономике и в управлении, результаты 
АНДРЕЕВ В. В., АНДРЕЕВ В. В.

ПСИХОЛОГИЧЕСКАЯ КОНЦЕПЦИЯ ПРЕОДОЛЕНИЯ: ТЕОРИЯ, МЕТОДОЛОГИЯ, ДИАГНОСТИКА

РосСИЙСКИй пСИХологИЧЕСКИй ЖУРнАл, 2019, Т. 16, № 3, 20-32. doi: 10.21702/rpj.2019.3.2

ОБЩАЯ ПСИХОЛОГИЯ, ПСИХОЛОГИЯ ЛИЧНОСТИ, ИСТОРИЯ ПСИХОЛОГИИ

исследования психологических барьеров в педагогике - Шакуров (2003), Подымов (1999), Brehm \& Weintraub (1977); многочисленные исследования проблемы риска представлены в работах Петровского (1992), Корниловой (2003), Kozielecki (1987) и других авторов. К объяснительным детерминантам сущности происхождения феномена преодоления следует отнести «рефлекс свободы» и «рефлекс цели» И. П. Павлова (Павлов, 1951, с. 481-485), «принцип доминанты» А. А. Ухтомского (Ухтомский, 1966), синергетические идеи «концепции неравновесных систем» И. Пригожина (Пригожин, 1991), теоретические положения П. К. Анохина, Б. Г. Ананьева, Н. А. Бернштейна, Э. С. Бауэра и других ученых.

1. Принцип противоречий. Введение в категориальный аппарат психологии принципа противоречий позволяет представить базовые психологические категории: отражение как основу когнитивных процессов, отношение как основу эмоциональных процессов, и регуляцию как основу волевых процессов в единой системе взаимосвязанных методологических принципов, а мотивационную, когнитивную, эмоциональную, поведенческую и соматические составляющие психики человека как его качественное разнообразие. Таким образом, категория преодоления приобретает фундаментальную теоретическую и методологическую основу, позволяющую раскрыть психологический смысл феномена «преодоление» на более высоком уровне абстракции. Стоит отметить, что принцип противоречий в явном или замаскированном виде присутствует в различных психологических и психотерапевтических концепциях.

В. Франкл (1990) писал, что сущность жизни и развития человека определена внутренними противоречиями, борьбой противоположных процессов между такими образованиями, как устойчивость/изменчивость, ассимиляция/диссимиляция, активность/пассивность, и эти противоречия вынуждают человека действовать в поисках его разрешения. В процессе творчества человек сублимирует трудности, выходит за границы самого себя как личности, за границы существующих возможностей и, преодолевая неопределенность, опасность и пассивность, аккумулирует собственные силы в целеустремленные системы и реализует ресурсы.

Давая определение человеку в своей интерпретации, В. Франкл утверждал, что человек представляет из себя субъект, стремящийся освободиться и преодолеть в себе все те детерминанты, которые его обуславливали ранее. То есть, это существо, которое превосходит все эти детерминанты (физические, биологические, психологические, социальные и духовные) либо побеждая их, либо трансформируя их по-другому, либо осознанно, по собственному желанию, им подчиняясь (Франкл, 1990).

На конструктивную природу личности, стремящейся к поиску и разрешению возникающих в процессе жизнедеятельности все более трудных проблем, указывал Г. Олпорт. В качестве условия развития личности он выделяет возможность К «сопротивлению равновесию» (Allport, 1937).

Метафорически рассуждая, личность человека можно представить в виде субъекта, действующего на разных уровнях, мощностях и скоростях, когда закономерности более высокого порядка могут преодолевать действие базовых, универсальных закономерностей подобно тому, как неподвижный физический объект (камень) преодолевает только пространственно-временные границы существования и законы гравитации, а передвигающийся объект (автомобиль), не отменяя законов гравитации, преодолевает их действие благодаря законам трения и тем самым преодолевает пространственно-временные границы существования неподвижного объекта, а летящий объект (самолет), не отменяя законов гравитации и законов трения, преодолевает их действие благодаря использованию законов более высокого 
АНДРеЕв В. В., АНДРЕев В. В.

ПСИХОЛОГИЧЕСКАЯ КОНЦЕПЦИЯ ПРЕОДОЛЕНИЯ: ТЕОРИЯ, МЕТОДОЛОГИЯ, ДИАГНОСТИКА

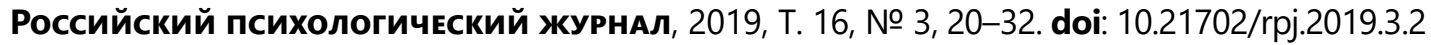

порядка - законов аэродинамики и, наконец, летящая ракета преодолевает законы тяготения, трения и аэродинамики за счет использования сил отталкивания от плотных слоев атмосферы, используя мощностной потенциал стартовых двигателей ракеты.

Франкл (1990) считал, что ограничения, действующие на физическом и психическом уровнях организации человека, преодолеваются на более высоком, духовном уровне. Тогда непроизвольный уровень поведения переходит в произвольный, а при увеличении нагрузки спокойный режим функционирования переходит в напряженный, напряженный переходит в режим усилия, а последний переходит в режим борьбы.

2. Принцип трансгрессии. Говоря о «выходе за ограничения», «выходе за пределы», ученые-исследователи, теоретики и практики используют такой значимый для нас термин как «переход» или трансгрессия (лат. trans - сквозь, через, за, и gressus - приближаться, переходить, нападать) - понятие, фиксирующее и отражающее ситуацию достижения и победы в процессе выполнения профессиональной деятельности, осуществляемой человеком на пике своих возможностей, в ситуации выхода за границы прежних достижений.

Ю. Козелецкий, описывая свою концепцию трансгрессии, считал, что независимо от будущей перспективы его концепции, будут или нет восприняты его идеи научным сообществом, изменят или нет свои представления о человеке, человек все равно останется таким, каким был до сих пор, т.е. субъектом, преодолевающим границы своих достижений, формирующим новые ценности и смыслы. Базовая трансгрессивная сущность человека никуда ни денется, иначе его как человека в подлинном смысле не будет существовать вообще (Kozielecki, 1987).

Анализируя психологию творчества, Пономарев (1994) писал о необходимости выхода за пределы достигнутых вершин в творчестве. Рассуждая о становлении и формировании нравственной личности, Чудновский (2006) говорил о необходимости выхода за пределы собственной личности, ну а выход за пределы реальной ситуации для Петровского (1992) явился концептуальной основой его теории «надситуативной активности».

Чаще всего противоречия могут выступать в психике и сознании человека: в виде физических препятствий (барьеров), если представить человека только как физическое тело, тогда результат преодоления физических ограничений (препятствий) приводит к физическому развитию человека; в виде биологических ограничений (стрессов), если рассматривать человека как биологическое существо (индивид), то результат преодоления биологических ограничений приводит к повышению защитных сил организма за счет голодания, закаливания, воздействия экстремальных температур, давления; в виде социальных ограничений (конфликтов), если фиксировать внимание на человеке как социальном существе (личность), то результат преодоления социальных ограничений приводит к улучшению межличностных отношений в команде, к формированию благоприятного психологического климата в спортивной команде, к решению социальных проблем; в виде духовно-нравственных ограничений (кризис), если изучать человека как индивидуальность, если рассматривать человека как микрокосм,- результат преодоления духовных ограничений может приводить к развитию личности, приобретению ею новых смыслов, идей, творчества.

Г. Гурджиев, рассуждая о трудностях в нашей жизни, утверждал, что они являются необходимыми нашими учителями, а анализ, изучение и преодоление (борьбу) своего главного недостатка (противоречия) следует представить в виде процесса самоактуализации и считать его основой по формированию структуры индивидуальности, которая вычерчивает судьбу и путь каждого человека (Успенский, 1992). Преодоление противоречий (недостатков) в жизни 
АНДРЕЕВ В. В., АНДРЕЕВ В. В.

ПСИХОЛОГИЧЕСКАЯ КОНЦЕПЦИЯ ПРЕОДОЛЕНИЯ: ТЕОРИЯ, МЕТОДОЛОГИЯ, ДИАГНОСТИКА

РосСИЙСКИй пСИХологИЧЕСКИй ЖУРнАл, 2019, Т. 16, № 3, 20-32. doi: 10.21702/rpj.2019.3.2

ОБЩАЯ ПСИХОЛОГИЯ, ПСИХОЛОГИЯ ЛИЧНОСТИ, ИСТОРИЯ ПСИХОЛОГИИ

человека, которое превращается в наши достижения, успехи и победы, можно считать основополагающим критерием в формировании «человека преодолевающего». Иначе говоря, противоречия в феномене воли выполняют детерминирующую функцию (входят в ее состав), которую можно рассматривать как причину процесса преодоления, а феномен преодоления можно представить как область психологии преодоления осознаваемых или неосознаваемых противоречий, которые выполняют функцию самодетерминации и саморегуляции.

\section{Уровни преодоления}

Общенаучный уровень методологии теории преодоления включает общефилософскую диалектическую концепцию развития (подчинение механизма преодоления законам и закономерностям отражения, детерминации, единства и борьбы противоположностей, перехода количественных изменений в качественные и обратно, отрицание отрицания); понимание преодоления как механизма развития, обусловленного противодействием, исходящим от внешней среды, и взгляд на преодоление как на активный, индивидуальный процесс взаимодействия со средой.

Феноменология преодоления имеет свое представительство в предельных экстремальных ситуациях, которые связаны с различными сферами деятельности человека: физической, биологической, социальной, морально-нравственной. Пиковые ситуации можно рассматривать в качестве предельного случая неравновесного состояния человека, которое развивается благодаря неустойчивости системы. Концепт преодоления должен быть организован иерархически, где качество и уровни преодоления зависят от уникальности человека, от профессиональной специализации, от уровня независимости, самостоятельности и ответственности человека (меры личностной самодетерминированности) и тех ценностей, мотивов и смыслов, которые он преследует в процессе преодоления экстремальных ситуаций. Шиповская (2013) отмечала, что многоуровневая модель преодоления позволяет представить феномен преодоления как стадии преодолевающего восхождения и преобразования в процессе переходов от одного уровня активности к другому.

1. Уровень психомоторной (психофизической) активности человека направлен на преодоление внешних и внутренних физических ограничений. К настоящему времени в психологии накоплен значительный эмпирический материал, отражающий некоторые аспекты проблемы психомоторики человека. Психомоторика - это объективизация всех форм психической активности через мышечные движения. «Смеется ли ребенок при виде игрушки, улыбается ли Гарибальди, когда его гонят за излишнюю любовь к родине, дрожит ли девушка при первой мысли о любви, создает ли Ньютон мировые законы - везде окончательным фактом является мышечное движение». Так писал великий русский физиолог И. М. Сеченов в вышедшей в 1863 г. монографии «Рефлексы головного мозга» (Сеченов, 1953, с. 174-179). Иначе говоря, в процессе преодоления физических ограничений (препятствий) осуществляется физическое развитие и совершенствование человека.

2. Индивидный уровень преодоления напрямую связан с преодолением стрессовых ситуаций. На индивидном уровне преодоления человек использует не только различные психологические защиты, но и различные виды биологических и физиологических ограничений (стрессы), в результате столкновения с которыми происходит повышение защитных сил организма: выход за нормы потребления жизненно важных веществ за счет ограничений в питании (голодание), выход за границы температурных норм (баня, сауна, закаливание, криотерапия) 
АНДРеЕв В. В., АНДРЕЕВ В. В.

ПСИХОЛОГИЧЕСКАЯ КОНЦЕПЦИЯ ПРЕОДОЛЕНИЯ: ТЕОРИЯ, МЕТОДОЛОГИЯ, ДИАГНОСТИКА

РосСИЙскИй псИХоЛОГИЧЕСКИй ЖУРНАл, 2019, Т. 16, № 3, 20-32. doi: 10.21702/rpj.2019.3.2

ОБЩАЯ ПСИХОЛОГИЯ, ПСИХОЛОГИЯ ЛИЧНОСТИ, ИСТОРИЯ ПСИХОЛОГИИ

за счет воздействия экстремальных высоких и низких температурных факторов среды, выход за границы воздействия гравитационных норм (барокамера, где моделируются различные условия атмосферного давления), и т.д.

Переживание как преодоление стрессовых ситуаций в жизни приводит к повышению стрессоустойчивости человека. Поэтому изучение структуры и динамики актуальных стрессовых переживаний в прошлом и настоящем, раскрытие феноменологии конкретных переживаний, знакомство с методами работы с «острыми» переживаниями, обучение человека методам и способам переживания острых ситуаций могут привести к повышению индивидной устойчивости и развитию личности.

3. Социально-психологический (личностный) уровень преодоления обусловлен условиями жизнедеятельности человека и связан с преодолением конфликтных ситуаций в жизни человека. Изучение профессиональных, социальных и психологических причин возникновения конфликтных ситуаций, знание структурно-динамических параметров поведения в конфликте, владение навыками поведения в конфликтах и методами выхода из конфликтных ситуаций приводят к повышению социально-психологической грамотности, повышению устойчивости к конфликтам и формируют навыки использования энергии конфликтных ситуаций в личностный рост.

4. Духовно-нравственный (индивидуальный) уровень преодоления связан с преодолением кризисных ситуаций в жизни человека и направлен на преодоление ограничений в структуре его ценностей. Преодоление кризисных ситуаций может способствовать личностному развитию человека. Знание алгоритма преодоления кризисов и способов трансформации негативной энергии кризиса в личностный рост дает возможность обучать студентов навыкам эффективного поведения в ситуациях личностного тупика.

Индивидуальный уровень преодоления определяется смысложизненным кризисом человеканевозможностью жить по-старому и непониманием поиска и выбора дальнейшей стратегии жизни (переживанием тупика), которое должно привести к понимаемой главной внутренней цели, выбору средств выхода за собственные границы в плане трансгрессивного поведения. Этот уровень отличается творческим подходом к профессиональной деятельности, выраженной ценностной и мотивационной включенностью и направлен на решение индивидуальных задач, преодоление отживших стратегий поведения, преодоление внутриличностного сопротивления. Выход за пределы духовных ограничений (кризисов) требует непрерывных усилий для реализации того «уникального», что необходимо человеку в данный момент и приводит к развитию личности, приобретению новых смыслов, идей, творчества, что позволяет человеку успешно реализовать собственную индивидуальность.

\section{Психологические составляющие и параметры процесса преодоления}

Процесс преодоления имеет комплексный характер и обнаруживает себя в четырех направлениях:

1. «Нужда» как базовая детерминанта (ограничитель) мотивационной активности человека (стремление к преодолению) представляет динамические процессы возникновения и исчезновение личностных мотивов, увеличение и уменьшение их интенсивности, способствует появлению антимотивов, антижеланий и антипотребностей, приводящих к борьбе мотивов, желаний и потребностей, и выход (преодоление) мотивационной активности за границы существующих «отработанных» мотивов к другим мотивационным установкам, которые и актуализируют ресурсы человека и приводят его к достижениям и победам. 
АНДРЕЕВ В. В., АНДРЕЕВ В. В.

ПСИХОЛОГИЧЕСКАЯ КОНЦЕПЦИЯ ПРЕОДОЛЕНИЯ: ТЕОРИЯ, МЕТОДОЛОГИЯ, ДИАГНОСТИКА

РосСИЙСКИй пСИХолоГИЧЕСКИй ЖУРнАл, 2019, Т. 16, № 3, 20-32. doi: 10.21702/rpj.2019.3.2

ОБЩАЯ ПСИХОЛОГИЯ, ПСИХОЛОГИЯ ЛИЧНОСТИ, ИСТОРИЯ ПСИХОЛОГИИ

2. «Неопределенность» как необходимый компонент (ограничитель) когнитивной активности человека (познание как преодоление неопределенности). Данная когнитивная составляющая процесса преодоления опирается на те жизненные проблемы, задачи и вопросы, которые формируют (активизируют, запускают, катализируют и определяют мыслительный процесс человека).

3. «Опасность» или «тревога» как ключевой параметр эмоциональной активности человека (переживание как преодоление тревоги). Эмоциональная составляющая процесса преодоления позволяет рассматривать переживание как процесс преодоления со своим набором психологических параметров.

4. «Дефицит или недостаточность» навыков и умений - является необходимым и явным компонентом поведенческой (coping-behavior) активности человека, направленной на преодоление физическо-технических и тактических недостатков в его профессиональной деятельности, влияющих на оптимальное протекание деятельности, вызванных как особенностями экстремальной ситуации данного вида профессиональной деятельности, так и особенностями личности человека. Поведенческая составляющая процесса преодоления будет представлена в различных стратегиях, техниках и методах преодоления.

\section{Результаты и их обсуждение}

Главные эмпирические данные по результатам семантического анализа феномена воли как преодоления были получены у студентов НГУ им. П. Ф. Лесгафта. Проблема воли комплексная, может быть представлена на 4-х уровнях активности психики и определяется по характеру тех противоречий, которые выступают в сознании личности студента в виде разнообразных ограничений: физических преград, психических стрессов, социально-психологических конфликтов и индивидуальных кризисов. Феноменология воли имеет 4-е переменные, обусловленные когнитивной, аффективной, мотивационной и поведенческой составляющими данного процесса.

Несомненно, знание сущности феномена преодоления, уровень развития способности к преодолению различных психологических противоречий, системный и комплексный характер воздействия ограничений на личность студента и механизм преодоления обуславливают эффективное формирование его характера. Результаты исследования феномена воли как преодоления в учебной деятельности студентов позволят разработать рекомендации по совершенствованию психологической подготовки студента и дадут существенный материал для разработки программы психологической подготовки по формированию воли современного студента, направленный на развитие новых знаний, умений и навыков преодолевающего поведения.

Для изучения субъективного восприятия феномена преодоления спортсменами различных специализаций был выполнен контент-анализ определений воли, которые были представлены в анкетных данных. Анализируя частоту встречаемости различных показателей психики, мы выяснили, что студенты чаще всего отмечали мотивационный компонент воли (15,94\%). На втором месте по частоте высказываний оказался критерий «преодоления ограничений» (15,4\%). Зафиксирована связь с волевыми качествами и свойствами $(10,7 \%)$. На динамическую характеристику воли, критерий «процессуальные характеристики», обратили внимание 9,6\%. Далее студенты выделили: поведенческий аспект (9,6\%), силовой аспект (6,7\%), регуляторный фактор (6,1\%), направленность на себя (5,8\%), «человек» $(5,8 \%)$, «сознание» $(4,9 \%)$, аспект свободы (4,1\%) (табл. 1). 
АНДРеЕв В. В., АНДРЕЕВ В. В.

ПСИХОЛОГИЧЕСКАЯ КОНЦЕПЦИЯ ПРЕОДОЛЕНИЯ: ТЕОРИЯ, МЕТОДОЛОГИЯ, ДИАГНОСТИКА

РосСИЙскИй псИХоЛОГИЧЕСКИй ЖУРНАл, 2019, Т. 16, № 3, 20-32. doi: 10.21702/rpj.2019.3.2

ОБЩАЯ ПСИХОЛОГИЯ, ПСИхОЛОГИЯ лИЧнОстИ, ИСТОРИя ПСИхОЛОГИИ

В результате интеграции полученных данных мы дали следующую общую характеристику воли. Воля - это позитивная направленность сознания человека, воплощенная в мотивах, направленных на преодоление ограничений; имеет выраженную процессуальную составляющую, тесно связана с поведением человека и обладает силовой компонентой, осуществляет процесс регуляции и стремится к свободе.

\begin{tabular}{|c|c|c|c|}
\hline \multicolumn{4}{|c|}{$\begin{array}{l}\text { Таблица } 1 \\
\text { Общая характеристика воли по результатам контент-анализа }(n=87)\end{array}$} \\
\hline $\begin{array}{l}\text { № } \\
\text { П/П }\end{array}$ & общая характеристика воли & Частотная характеристика & $\%$ \\
\hline 1 & Мотивационный аспект & 55 & $15,9 \%$ \\
\hline 2 & Преодоление ограничений & 53 & $15,4 \%$ \\
\hline 3 & Волевые качества и свойства & 37 & $10,7 \%$ \\
\hline 4 & Процессуальные характеристики & 33 & $9,6 \%$ \\
\hline 5 & Поведенческий аспект & 29 & $8,4 \%$ \\
\hline 6 & Позитивные аспекты & 23 & $6,7 \%$ \\
\hline 7 & Си^овой аспект & 23 & $6,7 \%$ \\
\hline 8 & Регуляторный аспект & 21 & $6,1 \%$ \\
\hline 9 & Направленность на себя & 20 & $5,8 \%$ \\
\hline 10 & Человек & 20 & $5,8 \%$ \\
\hline 11 & Сознание & 17 & $4,9 \%$ \\
\hline \multirow[t]{2}{*}{12} & Свобода & 14 & $4,1 \%$ \\
\hline & Итого & 345 & $100 \%$ \\
\hline
\end{tabular}

\section{Заключение}

1. Терминологический анализ понятия «преодоление» позволяет утверждать, что данный феномен отражается в явлениях напряжения, усилия, борьбы (уровни преодоления), связан с ощущением перехода, сдвига, «выхода за...», возможного лишь при наличии препятствий, связан с преодолением их сопротивления и означает высшую степень проявления какого-либо качества, позволяющего выйти за пределы конкретной ситуации, «пре-восхождение» возникающих на жизненном пути препятствий; осуществляет функцию контроля, защиты, совладания, жизнестойкости и тем самым мобилизует резервы, сохраняя свободу и развитие личности.

2. Функциональный анализ понятия «преодоление» показал, что это психологическое понятие отражает функцию детерминации и усилителя в развитие сознания человека, систематизирующее его субъективный мир, проявляющееся в виде когнитивных, эмоциональных, мотивационных и поведенческих процессов, выступающих для субъекта как психическая деятельность, направленная на преобразование показателей неопределенности, опасности, недостатков и неудовлетворенности в личностный рост. 
АНДРЕЕВ В. В., АНДРЕЕВ В. В.

ПСИХОЛОГИЧЕСКАЯ КОНЦЕПЦИЯ ПРЕОДОЛЕНИЯ: ТЕОРИЯ, МЕТОДОЛОГИЯ, ДИАГНОСТИКА

РосСИЙСКИй пСИХолоГИЧЕСКИй ЖУРнАл, 2019, Т. 16, № 3, 20-32. doi: 10.21702/rpj.2019.3.2

ОБЩАЯ ПСИХОЛОГИЯ, ПСИХОЛОГИЯ ЛИЧНОСТИ, ИСТОРИЯ ПСИХОЛОГИИ

3. Обобщая полученные эмпирические данные контент-анализа, мы предлагаем следующую интегральную характеристику воли:

Воля - это позитивная направленность сознания человека, воплощенная в мотивах, направленных на преодоление ограничений; имеет выраженную процессуальную составляющую, тесно связана с поведением человека, обладает силовой компонентой, актуализирует регуляторный процесс и детерминирует стремление к свободе.

\section{Литература}

Бауэр, Э. С. (1935). Теоретическая биология. Москва; Ленинград: ВИЭМ.

Гегель, Г. В. (1974). Энциклопедия философских наук. T. 1. Наука логики. М: Мысль.

Гумилев, Л. Н. (2001). Этногенез и биосфера Земли. Санкт-Петербург: Кристалл.

Гусейнов, А. Ш. (2017). Протестная активность личности (дисс. ... д. психол. наук). Краснодар.

Корнилова, Т. В. (2003). Психология риска и принятия решений: учебное пособие для студентов вузов. М.: Аспект Пресс.

Леонтьев, Д. А. (2011). Личностный потенциал. Структура и диагностика. М.: Смысл.

Магомед-Эминов, М. Ш. (2008). Феномен экстремальности (2-е изд.). М.: Психоаналитическая Ассоциация.

Мадди, С. (2002). Жизнестойкость, ее диагностика и тренинг. М.: Изд-во Института экзистенциальной психологии и жизнетворчества.

Мамардашвили, М. К. (1997). Психологическая топология пути. Санкт-Петербург: Изд-во РХГИ. Доступ 13 августа 2019, источник https://archive.ph/BtP34

Павлов, И. П. (1951). Физиологический механизм так называемых произвольных движений. В Двадиатилетний опыт объективного изучения высшей нервной деятельности (поведения) животных (С. 481-485). Москва.

Пакулина, С. А. (2010). Преодолевающая адаптация: системообразующий фактор и условие формирования самостоятельности студентов в вузе. М.: Изд-во СГУ.

Петровский, В.А. (1992). Психология неадаптивной активности. М.: ТОО «Горбунок».

Подымов, Н. А. (1999). Психологические барьеры в профессиональной деятельности учителя (дисс. ... д. психол. наук). Москва.

Пономарев, Я. А. (1994). Психология творчества: перспективы развития. Психологический журнал, 15(6), 38-50.

Пригожин, И. (1991). Философия нестабильности. Вопросы философии, 6, 46-52.

Разумовский, О. С. (1988). Экстремальные закономерности: Категории наибольшего и наименьшего. Новосибирск: Наука.

Рубинштейн, С. Л. (1997). Человек и мир. М.: Наука.

Сапогова, Е. Е. (2009). Преодоление лиминальности как способ личностного жизнетворчества. Культурно-историческая психология, 1, 49-56.

Сеченов, И. М. (1953). Избранные произведения. Москва.

Томалинцев, В. Н. (2007). Экстремаль России: прогноз развития. Санкт-Петербург: Фонд «Отечество».

Тульчинский, Г. Л. (2002). Постчеловеческая персонология. Новые перспективы свободы и рациональности. Санкт-Петербург: Алетейя.

Успенский, П. Д. (1992). В поисках чудесного. СПб: Издательство Чернышева.

Ухтомский, А. А. (1966). Доминанта. М.; Ленинград: Наука.

Ушинский, К. Д. (1953). Избранные педагогчческие сочинения: в 2 m. (Т. 2). М.: Минпрос РСФСР. 
АНДРеЕв В. В., АНДРеЕв В. В.

ПСИХОЛОГИЧЕСКАЯ КОНЦЕПЦИЯ ПРЕОДОЛЕНИЯ: ТЕОРИЯ, МЕТОДОЛОГИЯ, ДИАГНОСТИКА

РосСиЙский психологИЧЕский ЖУРнАл, 2019, Т. 16, № 3, 20-32. doi: 10.21702/rpj.2019.3.2

Франкл, В. (1990). Человек в поисках смысла. М.: Прогресс.

Чудновский, В. Э. (2006). Становление личности и проблема смысла жизни: избранные труды. Воронеж: НПО МОДЭК.

Шакуров, Р. Х. (2003). Психология смыслов: теория преодоления. Вопросы психологии, 5, 18-33.

Шиповская, В.В.(2013). Модусы преодолевающей активности личности в контексте субъектнобытийного подхода. Известия Сочинского государственного университета, 4-2(28), 89-93.

Allport, G. W. (1937). The functional autonomy of motives. American Journal of Psychology, 50, 141-156.

Brehm, S. S., \& Weintraub, M. (1977). Physical barriers and psychological reactance: Two-year-olds' responses to threats to freedom. Journal of Personality and Social Psychology, 35, 830-836.

Caplan, G. (1963). Emotional crisis. In The Encyclopedia of Mental Health. (Vol. 2, pp. 521-532). N.Y:: Franklin Watts, Inc.

Deci, E. L., \& Ryan, R. M. (1985). Intrinsic motivation and self-determination in human behavior. New York: Plenum.

Deci, E. L., \& Ryan, R. M. (1986). The dynamics of self-determination in personality and development. In R. Schvarzer (Ed.), Self-related cognitions in anxiety and motivation (pp. 171-194). Hillsdale, NJ: Erlbaum.

Deci, E. L., \& Ryan, R. M. (1991). A motivational approach to self: Integration in personality. In R. E. Diensbier (Ed.), Nebraska Symposium on Motivation (pp. 237-288). Lincoln: University of Nebraska Press. Retrieved at: https://www.researchgate.net/ publication/21026291 A Motivational Approach to Self Integration in Personality

Hobfoll, S. E., \& Lerman, M. (1988). Personal Relationships, Personal Attitudes and Stress Resistance: Mother's Reactions to the Child's Illness. American Journal of Community Psychology, 16(4), 565-589.

Kozielecki, J. (1987). Koncepcja transgresyjna czlowieka. PWN, Warszawa.

Kozielecki, J. (1995). Koncepcje psycholog iczne czlowieka. Warszawa: Wyd. Zak.

Kozielecki, J. (1997). Transgresja i kultura. Warszawa.

Kozielecki, J. (2001). Psychotransgresjonizm. Nowy kierunek w psychologii. Warszawa.

Kuhl, J. (1983). Motivation, Konflikt und Handlungskontrolle. Heidelberg: Springer.

Kuhl, J. (1994). Wille und Freiheitserleben: Formen der Selbststeuerung. In J. Kuhl, H. Heckhausen (Hrsg.), Enziklopadie der Psychologii. Motivation und Emotion (Bd. 4). Gottingen: Hogrefe.

Kuhl, J., \& Beckmann, J. (Eds.) (1994). Volition and Personality. Action vs. state orientation. Gottingen: Hogrefe. Lazarus, R. S., \& Folkman, S. (1984). Stress, appraisal, and coping. New York: Springer Publishing Company. Maddi, S. R. (1965). Motivational aspects of creativity. Journal of Personality, 33, 330-347.

Maslow, A. (1967). Self-actualizing and Beyond. In Challenges of Humanistic Psychology. New York.

Plutchik, R., Kellermann, H., \& Conte, H. R. (1979). A structural theory of ego defences and emotions. In C. E. Isard (Ed.), Emotions in personality and psychopathology (pp. 229-257). N. Y.: Plenum.

Ryan, R. M., \& Deci, E. L. (2000). Self-determination theory and the facilitation of intrinsic motivation, social development, and well-being. American Psychologist, 55(1), 68-78. doi: 10.1037/0003-066X.55.1.68

Ryan, R. M., \& Deci, E. L. (2002). An overview of Self-determination Theory: An organismic-dialectical perspective. In E. L. Deci, \& R. M. Ryan (Eds.), Handbook of self-determination research. (pp. 3-33). New York: The University of Rochester Press.

Ryan, R. M., Deci, E. L., \& Grolnic, W. S. (1995). Autonomy, relatedness, and the Self: their relation to development and psychopathology. In D. Cicchetti, D. J. Cohen (Eds.), Developmental psychopathology (Vol. 1, pp. 618-655). New York: Willey.

\section{Конфликт интересов отсутствует}

